\title{
Settlement-timing hypothesis: reply to Grant and Williamson
}

\author{
Christopher D. Todd \\ Department of Zoology and Marine Biology, Gatty Marine Laboratory, University of St. Andrews, St. Andrews, Fife, Scotland \\ KY16 8LB, United Kingdom
}

\begin{abstract}
It is maintained that in order for our hypothesis (Todd \& Doyle 1981) to be upheld it is not necessary that both optimal spawning date and optimal settlement date are closely determined by environmental conditions' and that 'evidence is (not) lacking... in the species examined by (us)' (Grant \& Williamson 1985). Nevertheless, it is accepted that more detailed additional data on the pelagic larval stage of Onchidoris bilamellata, at ambient field temperatures, would be of considerable value in clarifying some of the issues raised in Grant \& Williamson's critique.
\end{abstract}

\section{INTRODUCTION}

Todd \& Doyle (1981) propose an hypothesis (i. e. 'an assumption providing an explanation of observed facts, proposed in order to test its consequences; an assertion or working explanation that leads to testable predictions', Lincoln et al. 1982). Our submission should mot be taken as a theory ("a scientifically accepted principle supported by a substantial body of evidence ... Lincoln et al. 1982). Grant \& Williamson (1985, their abstract) appear to have missed this distinction and seem to have not clearly understood our second paragraph, in which we stated '... the settlement-timing hypothesis... purports not to explain why every benthic marine invertebrate species has adopted a particular strategy, rather how development time may be the balancing or determining factor in instances where 2 or more strategies appear optional in energetic terms'.

The nudibranch Onchidoris bilamellata (L.) is boreopanarctic (Thompson \& Brown 1984) reaching its southern limit in Europe on the French coast near Le Croisic (Bouchet \& Tardy 1976): this approximates the southern limit of the barnacle Balanus balanoides (L.), a major prey item for the nudibranch. Nevertheless, $O$. bilamellata will take a wide variety of other barnacles including $B$. crenatus Bruguière, B. balanus (L.) and Elminius modestus Darwin (for reviews see Todd 1981 and McDenald 1983). Thus, while mid-shore populations of $O$. bilamellata are associated with $B$. balanoides it is evident that lower intertidal and sublit- toral populations are increasingly reliant upon $B$. crenatus.

Our original hypothesis was broadly formulated as a possible explanation for the observed life-cycle and larval strategy of this species in the littoral zone on the northeast coast of England. Metamorphosis of the planktotrophic veliger larva will only be triggered by contact with live barnacles (Todd 1981). Furthermore, although adult Onchidoris bilamellata would occasionally take the asymmetrical barnacle Verruca stroemia (O. F. Muiller), post-metamorph juveniles were found to be incapable of handling this species. Juveniles offered only $V$. stroemia failed to grow and died, indicating that in the absence of suitable cirripede prey temporary subsistence on, for example, detritus is not possible (Todd 1979). Successful laboratory culture (at elevated temperature) and metamorphosis of $O$. bilamellata preceded the availability of barnacle cyprids and spat in the field and, in consequence, detailed observation of post-metamorphic feeding has not been possible. Nevertheless, the unavoidable deduction from the above, and other sources cited therein, is that $O$. bilamellata will only metamorphose in the presence of the prey and that the availability of cyprids and/or spat is necessary for the successful establishment of the benthic individual. Balanus balanoides and $B$. crenatus are available, at such sizes, for only a few weeks of the year. In addition, spawning of benthic adults has been repeatedly observed around the British Isles commencing in midwinter some months prior to the settlement of barna- 
cles. Consideration of the differing egg-to-benthic juvenile periods conferred by the 3 fundamental larval strategies (planktotrophy, pelagic lecithotrophy, nonpelagic lecithotrophy) showed only long-term planktotrophy to be capable of 'bridging' the time-period between observed spawning and estimated/observed settlement. That there is a more-or-less restricted (but geographically and locally temporally variable) availability of essential prey is not in dispute: Grant \& Williamson (1985) do, however, argue against environmental dictation of a precise optimal spawning time.

Grant \& Williamson's (1985) objections are answered in the order in which they appear in their text, and I then reiterate the case in clarification and support of our original submission. Before doing so, however, there are 3 points of detail in their critique which necessitate appraisal: (1) In the mid-shore population (1975-76) (Todd 1979), for which egg production was quantified, spawning covered the period December-March/April and January output ( $37 \%$ of spawns) alone amounted to $50 \%$ of the egg total. (2) The citing of faunal list 'data' of spawning behaviour (e. g. Bruce et al. 1963, Laverack \& Blackler 1974) is unacceptable: such observations are invariably casual or, at best, anecdotal and of little quantitative value. (3) Grant \& Williamson's figured data of Balanus balanoides settlement are apparently imprecise (R. S. Bowman, J. R. Lewis pers. comm.) and incorrect. Including data for 1967 and 1982-1984 the timings of first settlement should read:

Early April: 1983

Late April: $1967,1968,1970,1972,1978$

Early May: 1969, 1971, 1973, 1974, 1975, 1977, 1981, 1982,1984

Late May: 1976,1980

Early June: 1979 (R. S. B., J. R. L. pers. comm.)

Furthermore, except for 1978-1981 - when daily counts were made - these data were based on counts of metamorphs every fortnight, and 'peak' settlement there is defined as the data by which new cyprid input balanced mortality of previously settled larvae. With the exception of 1970-1972 (when settlement was very dense) and the post-1978 years the recorded 'peak' settlement may be up to $2 \mathrm{wk}$ late.

\section{LENGTH OF DEVELOPMENT}

The data for the 30 species in Fig. 2 of Todd \& Doyle (1981) reproduced opposite in Fig. 1A are mostly for nudibranchs from the British Isles (23 species). Data for 3 species, Tergipes tergipes (Forskal), Eubranchus doriae (Trinchese), Aeolidiella alderi (Cocks) are from the northern Atlantic coast of France, while 2 observa- tions, Cuthona nana (Alder \& Hancock) and Coryphella stimpsoni (Verrill), are from New England, USA; those for Tenellia pallida (Alder \& Hancock) derive from Denmark and North Carolina, USA. The data for Precuthona peachii/Cuthona nana are discussed in our original text. The inclusion of these 7 observations (although all species except $C$. stimpsoni are recorded from the British Isles) was thus intended to merely increase the 'sample' sizes for the lecithotrophic categories in our figure, in order that the trends apparent among the 23 British observations might be clarified. It is accepted that local adaptation to temperature (e. g. Dehnel 1955) is likely, but I maintain that species cultured at temperatures above and below ambient will, nonetheless, develop more quickly and slowly respectively. Our $Q_{10}$ 'correction' (or, rather, 'standardization') simply intended to resolve these difficulties in cited data. Fig. 1B shows the observed development times at reported temperatures. The 2 scattergrams are essentially similar but in Fig. 1B some species do show some transposition, usually due to anomalously high laboratory temperatures. Indeed, Eyster (1979) emphasizes that her observations of $T$ pallida in the laboratory $\left(15^{\circ} \mathrm{C}\right)$ are at temperatures in excess of field ambient $\left(8\right.$ to $12{ }^{\circ} \mathrm{C}$ ). I reiterate (Todd \& Doyle 1981, p. 81) 'Since, however, in the present case we are concerned with the gross temporal differences in egg-to-juvenile periods conferred by the three reproductive strategies, such ('correction') error is not considered to be important'.

These data are of central, not 'marginal', relevance to the hypothesis and are corroborated by further laboratory observations of total egg-to-benthic juvenile periods at $10^{\circ} \mathrm{C}$ (Todd \& Havenhand 1985): Onchidoris muricata Müller, $90 \mu \mathrm{m}$ eggs, planktotrophic larvae, 72d; Archidoris pseudoargus (Rapp), 140 $\mu \mathrm{m}$ eggs, planktotrophic larvae, $67 \mathrm{~d}$; Adalaria proxima (Alder \& Hancock), $165 \mu \mathrm{m}$ eggs, pelagic lecithotrophic larvae, $36 \mathrm{~d}$.

Mean sea temperature data from the Bell Rock (North Sea) support our use of a mean of $6^{\circ} \mathrm{C}$ in adjusting the larval period for Onchidoris bilamellata. For example, mean temperature over the period January-May was $6.1^{\circ} \mathrm{C} \pm 0.7 \mathrm{C}^{\circ}$ (s. e.) in 1978 , while for 1979 this was $5.2^{\circ} \mathrm{C} \pm 0.5 \mathrm{C}^{\circ}$ (s. e.). While acknowledging the possibility of differing embryonic and larval $\mathrm{Q}_{10}$ 's (Sprung 1984, Todd \& Havenhand 1985), I presently stand by our adjustment of the pelagic phase of $O$. bilamellata from laboratory to (lower) field temperatures on the basis of $Q_{10}$ data for the intra-capsular phase of this same species. Nevertheless, we still require detailed observations of larval development of $O$. bilamellata, at field temperatures, in order to clarify these adjustments and predictions. Of particular relevance here may be the observation (Todd \& Doyle 

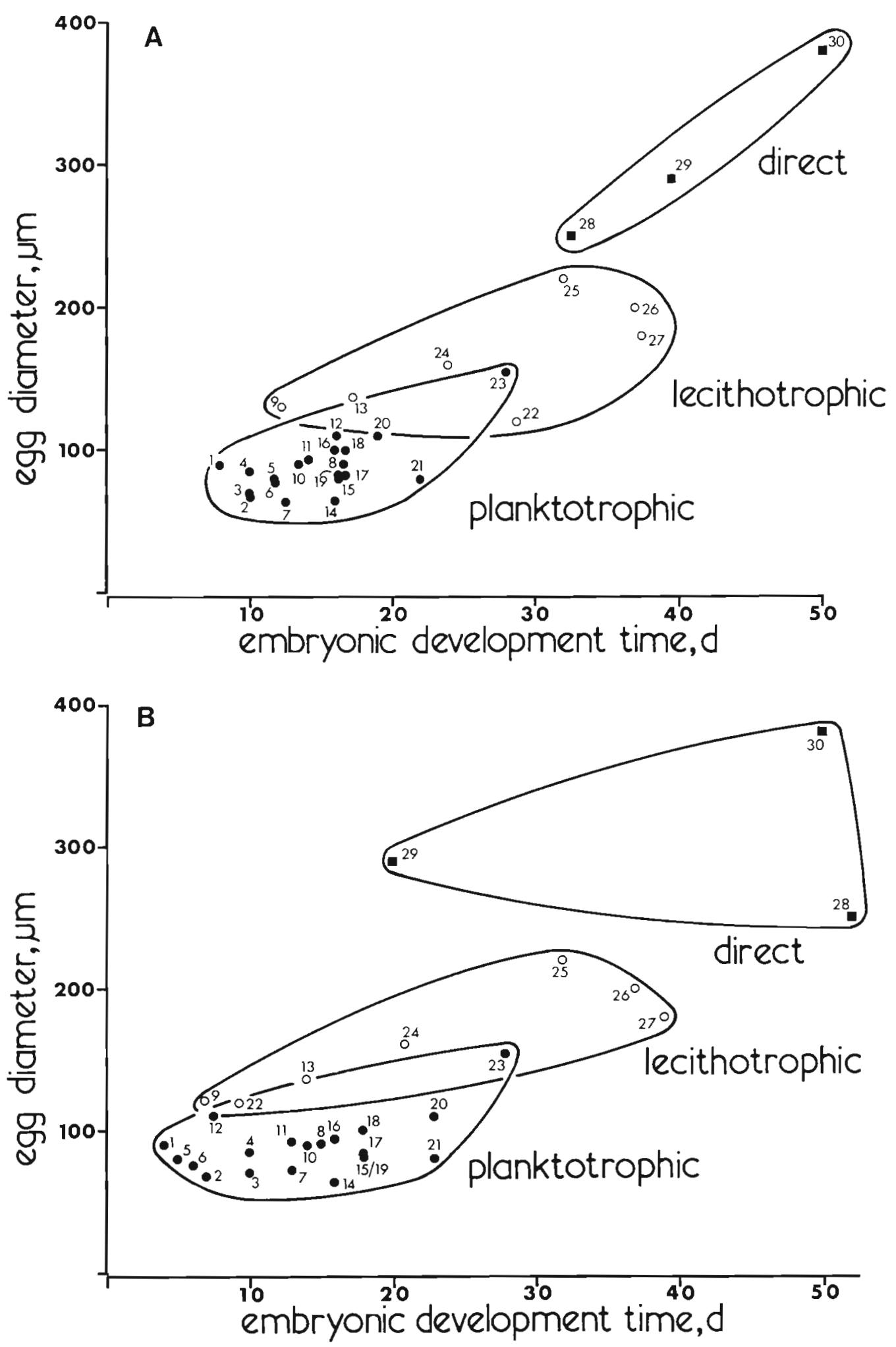

Fig. 1. Capsular development time for 30 species of North Atlantic nudibranchs. (A) 'adjusted' to $10^{\circ} \mathrm{C}$, using a common $Q_{10}$ of 2.34 (Fig. 2 of Todd \& Doyle 1981); (B) at reported temperatures from original sources 
1981, Fig. 1) that embryonic development of $O$. bilamellata is disproportionately slow at 4 to $5^{\circ} \mathrm{C}$. Larval culture experiments (at $5^{\circ} \mathrm{C}$ ) are presently in progress and intended specifically to resolve this issue.

The variability of time required for larvae to attain competence to metamorphose in laboratory culture is well-documented. Our data are no exception and the calculations were based on the fastest-developing larvae in culture. Recently Pechenik (1984) has shown that Crepidula fornicata (L.) larvae in culture grow at variable rates and that the slower-growing individuals not only attain competence later, but have absolutely (but not relatively) longer 'delay' phases. At first glance this might suggest that slower-growing genotypes are selectively favoured in that their opportunities of locating the correct benthic substratum for metamorphosis may be enhanced. Consideration must, however, be given to the decreased probability of such genotypes surviving to attain competence. I thus remain unmoved in our interpretation of the presently available larval development data for Onchidoris bilamellata.

Our original calculations indicated peak settlement of Onchidoris bilamellata to be May 3 (assuming peak spawning in 'mid-January'): this date has never been intended as an absolute, merely an indicator of mean behaviour (e.g. Todd \& Doyle 1981, Fig. 5). I am not yet in a position to apply an error term to this 'date' but hope to provide some measure thereof from laboratory larval studies still in progress.

\section{OPTIMAL SPAWNING AND SETTLEMENT TIMES: THE EVIDENCE}

Grant \& Williamson (1985) give the impression that nudibranchs spawn once and die: this is not so. Onchidoris bilamellata is semelparous yet dies after spawning several to many times over a continuous period of weeks. Fecundity is allometric with body size and there is, therefore, an apparent selective advantage in $O$. bilamellata delaying maturity, growing larger, and making a greater contribution to the gene pool. The probability of an individual surviving to greater age and size (Todd \& Doyle 1981, Fig. 3a) is such that January-February appears to represent what we have termed the 'optimal time to spawn' in that this implies the highest probability of attaining the largest size for individuals within the population. This point we illustrated (Fig. 3) by using population (biomass) data to summarize the integral of individual growth rate versus per capita mortality rates. This is not to suggest that selection can act upon populations, rather to show that there is variability between individuals behaving similarly.
Not all individuals within a given population commence spawning at the same time: maturity in Onchidoris muricata (and probably $O$. bilamellata) follows a size:age interaction (Todd 1978) in that there are minimum sizes and ages, both of which must be exceeded before gametogenesis commences. In consequence, for this reason alone, there will be variation in timing of maturity of individuals within a population. Moreover, $O$. bilamellata requires at least one copulation between spawnings, and otherwise mature individuals maintained in isolation throughout their lives delay first spawning (Todd 1979). Clearly there are endogenous (perhaps endocrine) factors implied here and these observations indicate the importance of population effects on individual reproductive performance in these hermaphrodite molluscs. Also of relevance is the observation (Todd 1979) that for $O$. bilamellata in ELWS habitats first spawning was observed perhaps a month later than for mid-tide level individuals. The precision of this difference is questionable due to the inaccessibility of lower shore populations but there appears to be the implication of environmental factors here. It was suggested that midshore $O$. bilamellata (exposed on aerial surfaces) are subject to more extreme light and temperature regimes and that this may explain this behavioural contrast. Low-shore individuals are, however, subject to intense intra-specific competition for prey (barnacles) and, in being smaller and slower-growing than their midshore counterparts (which encounter abundant prey), these may demonstrate delay of first reproduction for the reasons of size and age discussed above.

For all these reasons there will, within a population, be some variability among individuals in the size and age (i.e. timing) at which spawning commences, in response to both exogenous and endogenous factors. I have no experimental data but on the strength of extensive observations (Todd 1979), in conjunction with data from elsewhere (e.g. Swennen 1961, Miller 1962, Potts 1970), it is clear that Onchidoris bilamellata commences spawning at the coldest time of year. The 2 obvious environmental 'cues' are photoperiod and temperature. Mean monthly North Sea temperatures and daylength are virtually invariate between December and February. Such cues, if they are implicated, would not induce any precision in the initiation of spawning - especially in concert with the additional factors outlined above.

In summary, we must expect some variability of individual behaviour in the initiation of spawning activity. Individuals may, over a period of weeks, produce several spawn-masses but the earliest are generally the largest. In essence, peak individual egg production occurs in mid-January although additional spawning by some individuals may persist into April 
(e.g. Todd 1979, his Fig. 16). Even assuming that the environmental spawning cue relates to low, or even lowest, temperature (as expected for a 'northern' species approaching its southern limits) genotypes which spawn early one year would not necessarily confer early spawning in subsequent offspring due to the additional extrinsic influences outlined above.

I maintain, therefore, that there is a more-or-less extended period where spawning activity is promoted and that this period is some months prior to the availability of post-metamorph prey. The timing of these two events is independent but selection will favour those genotypes which, by their reproduction, bridge the gap and match the prey behaviour most frequently.

\section{BARNACLE SETTLEMENT TIMES}

Grant \& Williamson (1985) imply that the optimal time for Onchidoris bilamellata to settle is at the peak availability of cyprids, and suggest that more often than not this will be too late for the nudibranch metamorphs at Robin Hood's Bay. I would argue that the crucial factor for $O$. bilamellata is settlement coincident with the availability of Balanus balanoides that is, first settlement onwards - since newly metamorphosed nudibranchs require perhaps only a very few initial prey in order to attain a size adequate to handle older barnacles (a $2 \mathrm{~mm}$ mollusc can handle a $2 \mathrm{~mm}$ barnacle). While acknowledging the imprecision in the barnacle settlement data presented by Grant \& Williamson (1985) it is apparent that $O$. bilamellata would be well-adapted to match the timing of at least the first B. balanoides input. Moreover, $B$. crenatus - which has a coincident, but more extended, recruitment period (Crisp \& Patel 1969, Todd unpubl.) - may well provide a 'safety net' for newly metamorphosed nudibranchs in the lower intertidal. However, the markedly reduced littoral recruitment of $B$. crenatus (Todd unpubl.) can, at best, only provide a supplement to the primary mid-shore prey species. Thus, predictions of total failure based on $B$. balanoides data alone are less compelling than Grant \& Williamson suggest. Nevertheless, 1979 would clearly have been a critical year for $O$. bilamellata at Robin Hood's Bay due to the lateness of $B$. balanoides input. It should be emphasized that this was only one out of $17 \mathrm{yr}$, and that Robin Hood's Bay (being the latest locality of $B$. balanoides recruitment in the British Isles) presents this predator with extreme recruitment problems. Nonetheless, 1976 (which was a 'late year for $B$. balanoides) proved to be one of very high $O$. bilamellata recruitment. Furthermore, since nudibranch larval input is clearly from other sources, such (intermittent) local failures are of little ecological significance to an annual predator with pelagic larvae.

\section{DISCUSSION}

While Grant \& Williamson (1985) provide some useful and stimulating comments with respect to our hypothesis I find some of their criticisms and conjectures wanting. The settlement target for mid-shore Onchidoris bilamellata (Balanus balanoides metamorphs) is restricted but somewhat variable in time (Todd \& Doyle 1981, Fig. 5). This target is disjunct by some months from the time at which individual adults spawn (perhaps cued by environmental temperature). For the reasons outlined above there is variability in the timing of initial spawning and the duration over which individuals reproduce. Factors influencing 'early' or 'late' spawning during the December-February period are probably not heritable but selection will favour those genotypes which match $B$. balanoides most frequently. This very variability (geographical and temporal) in $B$. balanoides recruitment necessitates a spreading of the individual predator's larval output and calculations show that of the larval strategy 'options' only long-term planktotrophy can bridge the gap for this species. Precise timing of these 2 independent events (predator spawning and prey recruitment) is not necessary for the hypothesis to be substantiated. By the spreading of reproductive allocation over a period (while nonetheless producing more eggs earlier in the spawning period) $O$. bilamellata individuals maximize their probability of hitting the (moving) target in a manner analogous to the advantages of shotguns over rifles.

Acknowledgements. I thank J. R. Lewis, J. N. Havenhand and S. C. Kempf for thoughtful discussion and constructive criticism of early drafts of the manuscript, and R. S. Bowman and M. A. Kendall for the provision of unpublished data.

\section{LITERATURE CITED}

Bouchet, P., Tardy, J. (1976). Faunistique et biogéographie des nudibranches des côtes Françaises de l'Atlantique et de la Manche. Annls Inst. océanogr. 52: 205-213

Bruce, J. R., Colman, J. S., Jones, N. S. (1963). Marine fauna of the Isle of Man. Liverpool University Press, Liverpool

Crisp, D. J., Patel, B. (1969). Environmental control of the breeding of three boreo-arctic cirripedes. Mar. Biol. 2: 283-295

Dehnel, P. A. (1955). Rates of growth of gastropods as a function of latitude. Physiol. Zool. 28: 115-144

Eyster, L. S. (1979). Reproduction and developmental variability in the opisthobranch Tenellia pallida. Mar. Biol. 51: 133-140

Grant, A., Williamson, P. (1985). The settlement-timing hypothesis: a critique. Mar. Ecol. Prog. Ser. 23: 193-196

Laverack, M. S., Blackler, M. (1974). Fauna and Flora of St. Andrews Bay. Scottish Academic Press, Edinburgh

Lincoln, R. J., Boxshall, G. A., Clark, P. F. (1982). A dictionary of ecology, evolution and systematics. Cambridge University Press, Cambridge 
McDonald, G. R. (1983). A review of the nudibranchs of the California coast. Malacologia 24: 114-276

Miller, M. C. (1962). Annual cycles of some Manx nudibranchs, with a discussion of the problem of migration. J. Anim. Ecol. 31: 545-569

Pechenik, J. (1984). The relationship between temperature, growth rate, and duration of planktonic life for the larvae of Crepidula fornicata (L.). J. exp. mar. biol. Ecol. 74 : 241-257

Potts, G. W. (1970). The ecology of Onchidoris fusca (Nudibranchia). J. mar. biol. Ass. U. K. 50: 269-292

Sprung, M. (1984). Physiological energetics of mussel larvae (Mytilus edulis). III. Respiration. Mar. Ecol. Prog. Ser. 18: 171-178

Swennen, C. (1961). Data on distribution, reproduction and ecology of the nudibranchiate molluscs occurring in the Netherlands. Neth. J. Sea Res. 1: 191-240
Thompson, T. E., Brown, G. (1984). Biology of Opisthobranch molluscs, Volume II. Ray Society, London

Todd, C. D. (1978). Gonad development of Onchidoris muricata (Müller) in relation to size, age and spawning. (Gastropoda: Opisthobranchia). J. moll. Stud. 44: 190-199

Todd, C. D. (1979). The population ecology of Onchidoris bilamellata (L.). J. exp. mar biol. Ecol. 41: 213-355

Todd, C. D. (1981). The ecology of nudibranch molluses. Oceanogr. mar. Biol. A. Rev. 19: 141-234

Todd, C. D., Doyle, R. W. (1981). Reproductive strategies of marine benthic invertebrates: a settlement-timing hypothesis. Mar. Ecol. Prog. Ser. 4: 75-83

Todd, C. D., Havenhand, J. N. (1985). Preliminary observations on the embryonic and larval development of three species of dorid nudibranchs. J. moll. Stud.: in press 